\title{
Co-creation, contexts, and complexity: a case study concerning blended learning
}

\author{
Dave Burnapp, Rob Farmer, Sam Reese, Anthony Stepniak \\ University of Northampton
}

\section{Introduction}

This case study arises from a teaching and learning innovation project at the University of Northampton in the UK during a period of substantial institutional change. This project specifically concerned the development of blended learning activities for a first-year undergraduate module in linguistics and involved engaging students as partners in the research being carried out for the eventual module redesign. The students' roles hence moved from being passive responders (giving feedback on the acceptability of the approaches presented to them) to becoming active agents (creating suggestions about approaches they believed beneficial to their learning). This active agent role was clearly outlined in the participation invitation sent to all of the students currently studying this module:

"We really want the student research participants to be active in suggesting how the activities (the online platforms, the social media tools, indeed everything related to the blended learning portion of the module) can be adapted or modified to improve the students' learning experience. For the students who take part, this will be an opportunity to be an active participant and shaper of the changes the University of Northampton is engaged upon."

This paper will not cover the specific findings relating to the learning and teaching approaches being developed, but will explore three areas relating to establishing this form of partnership among staff and students: firstly, an exploration of why this approach was chosen; secondly, a description of how this partnership was maintained (relating both to ethical issues and to practicalities); thirdly, a summary of suggested guidance and lessons learnt, which we should like to share with others both within the University of Northampton and in the wider Higher Education (HE) sector to encourage them to consider such partnerships.

\section{Approach}

The innovation in question was a response to an institution-wide strategy which required staff to redesign modules and programmes for blended learning, i.e. including both face-toface and online delivery. In preparing the intervention, we identified previous projects where students had initially been seen as pedagogic consultants - to review course amendments proposed by academic staff (Money et al., 2016) - and then became more proactively involved in the construction process. McPherson and Heggie (2015) stress the advantages that come from the involvement of students in these ways: making them active agents, engaging them as active learners and, in consequence of these, establishing them as pedagogic partners. The team - consisting of two lecturers, a learning designer, and a research assistant - was hence determined to ensure collaborative engagement of students, not simply as a research sample to respond to the experimental learning activities, but 


\section{Case Studies}

rather, by means of created roles, as a group of agentive co-creators of the eventual redesigned module.

A key concept in sociolinguistics is 'context of situation', derived from Malinowski (1994 [1923]). This concept explains that an analysis of the language of any text (in this case, the strategic directives emanating from the university centre, or the contributions of individual students to online discussions about course materials, or texts such as this case study, written by academics trying to make sense of what is going on) is never in itself adequate to carry complete meaning. It is always necessary to know what is going on around the specific use of language: "Context of situation refers to the whole set of external-world features considered to be relevant in the analysis of an utterance" (Crystal, 2008, p. 109).

Institutionally, the context of situation of the requirement for staff to redesign their learning and teaching activities is itself a corollary of preparing to move to a new campus. This pedagogic requirement is hence but one of many facets of a much larger project involving major financial investments and implicating every aspect of the institution. It should be noted that the impetus for this pedagogic change came from the institutional centre, yet the responsibility for compliance was placed on individual module leaders.

For academic teaching staff, at least two other sets of constraints - beyond the institution itself - contribute to creating their professional context of situation: one is 'The UK Professional Standards Framework for teaching and supporting learning in higher education', led by the Higher Education Academy (HEA, 2011); the other is 'The UK Quality Code for Higher Education', led by the Quality Assurance Agency (QAA, 2015). Although both of these frameworks are concerned with assuring the maintenance of quality in HE in the UK, their interaction can place individual academics on the horns of a dilemma.

The first horn of the dilemma concerns the HEA framework, which intends to promote excellence amongst individual practitioners. For example, it includes, as an area of activity, 'Design and plan learning activities and/or programmes of study', which is clearly relevant to the materials development activity in this project. Another area is: 'Engage in continuing professional development in subjects/disciplines and their pedagogy, incorporating research, scholarship and the evaluation of professional practices', which is relevant to the project team's researching the acceptability of the innovations. The overall ethos to which this framework belongs is that of reflective practice and continuing professional development, which may be thought of as outward-directed, innovative imperatives. Yet the HEA framework also states that such activities must also conform to 'Professional Values', including 'Acknowledge the wider context in which higher education operates recognising the implications for professional practice'. An expected area of 'Core Knowledge' includes 'The implications of quality assurance and quality enhancement for academic and professional practice with a particular focus on teaching'.

Those 'Professional Values' link directly to the other horn of the dilemma, the QAA quality code, which has impact upon teaching staff by its application in universities in the form of rigorous procedures to be followed, in this case by a tightly-prescribed process prior to obtaining approval for any changes in module structure. Although individual module leaders may be responding to a directive from the highest levels of their institutional management, they are still accountable for ensuring compliance with quality assurance standards. This process necessitates consultation with a wide range of stakeholders, including colleagues, 


\section{Case Studies}

line managers, current students, prospective students, collaborative partners, professional bodies and benchmarking statements.

So, in brief, the overall ethos of quality assurance processes, in contrast to that of continuing professional development described above, may be thought of as inward-directed rather than outward-directed, as conserving and reluctant to change rather than innovative; hence the dilemma.

A possible perspective for observing and reflecting on this situation is that of a learning organisation, which has been advanced as an ideal to be emulated by organisations responding to changing situations. Features of learning organisations (including firms and universities) include operating in situations of continuous change which need to managed and guided: "Learning organizations are characterized by total employee involvement in a process of collaboratively conducted, collectively accountable change directed towards shared values or principles" (Smith, 2001, 2007). This commonality and collectivity invokes a need for what are often referred to as 'systemic activities' (systemic thinking, systemic change) which, if achieved, will bring alignment and coherence to the whole of a complex organisation.

Looking specifically at HE, a university is a complex system: "The core concept of a system is that it is composed of relationships among interdependent components that together comprise the whole" (Watson and Watson, 2013, p.44). It can be understood that large-scale changes must necessarily involve all component parts of the system, ideally acting in harmony but possibly at times conflicting and creating tensions. Watson and Watson (op.cit.) propose that systemic change is a pre-requisite for universities to respond to current pressures to fit a new paradigm: "Systemic change is a body of thinking concerned with the design of an entirely new system rather than trying to 'fix' a system that was never designed to deal with the challenges and processes it currently faces" (ibid. p.43).

Cohen et al. (2007) describe one approach to educational research as coming from a "paradigm of complexity systems" which has a focus on interconnections: "complexity theory suggests the need for case study methodology, action research, and participatory forms of research, premised in many ways on interactionist, qualitative accounts, i.e. looking at situations through the eyes of as many participants or stakeholders as possible" (Cohen et al., 2007, p.33). Cohen's description of research within this paradigm is dense with terms which chime with the intentions of this project team, which from the outset was determined to involve the students as active participants. Cohen talks of "interconnected networks", "necessary dynamic interaction of several parts", "collaborative and multi-perspectival approaches", and "research to catch the deliberate, intentional, agentic actions of participants."

\section{Method}

The overall research design was submitted to, and received approval from, the faculty research ethics process. An ethical dilemma which needed to be overcome in the planning stages concerned the possible ambiguity of academics' occupying a dual role in relation to their students; of being simultaneously teachers/assessors as well as researchers/partners. Therefore, in order to ensure full and frank reporting of the student experience, the project employed a postgraduate research assistant to collect data from the undergraduate 


\section{Case Studies}

students, so placing a buffer of anonymity between the teachers and the students in order to comply with necessary ethical considerations. This research assistant was responsible for recruiting the undergraduate students who became the project partners and so the teachers did not know which students from amongst the total cohort were taking part in the collaboration. The research assistant was also responsible for anonymising all data before giving it to the academic staff. The project funding allowed for ten students to be recruited, and each to be paid for four hours for their participation. This consisted of taking part in online discussions concerning aspects of the blended learning approaches used in the module and responding by email to specific questions sent to them by the project researcher.

Nine steps were followed while engaging the students:

\section{Step one}

In order to recruit undergraduate participants, the module tutors used the module virtual learning environment (VLE) to announce the project, giving the postgraduate research assistant's email address so that interested students could make contact. The tutors explained that they would not have direct contact with any participants both for ethical reasons and so that the data would not be compromised.

\section{Step two}

Those who volunteered were sent an information sheet constructed by the project leaders and approved by the project team.

\section{Step three}

The research assistant clarified details such as commitment and payment and emailed volunteers a link to the online consent form.

\section{Step four}

Ten students completed the consent form and the research assistant collected their completed forms as pdfs.

\section{Step five}

The research assistant then ensured that they were all fully registered with the temporary worker employment agency through which the participants would be employed and paid. Within two weeks, all had fully registered.

\section{Step six}

At this stage, there was a non-compulsory focus group meeting, involving the research assistant and the participants, as it was felt that it would be beneficial to have one face-toface session as an official start to the project and also as an opportunity to handle any unresolved issues or concerns that the participants had not previously mentioned. Owing to timetable constraints, there were two focus group meetings, with participation by eight of the participants. 


\section{Case Studies}

\section{Step seven}

The project team had agreed that online discussion would be the best means of data collection. The research assistant first considered using Facebook, but felt that, despite the ability to set up a private group chat, the site lent itself too much to informality and thus would be suitable neither for the project nor for the themes to be discussed. Eventually, participants were enrolled on a dedicated University VLE discussion board created exclusively for project discussion, ensuring both privacy and an appropriate platform for addressing the themes.

\section{Step eight}

Over several weeks, the research assistant updated the discussion board with regular prompts and questions, working from a schedule of topics which the project team had drawn up. Initial discussion questions were designed to elicit from students their prevalent uses of social media, for example:

In general, for what areas of your life - apart from education - do you engage with social media?

Do you differentiate between forms of social media depending on the purpose of the engagement and the person with whom you are engaging?

Other questions sought their responses to the pilot materials, for example:

Did you think there was a wide variety of media used on the online pod?

Did you have any difficulty understanding any of the tasks? ([...] whether yes or no, please give an example in your answer).

As the research progressed, they were then invited to make active suggestions for alternatives and improvements. For example:

Do you have any suggestions of any other forms of blending learning which could be used in this type of module?

Was the set-up / introduction to this particular set of materials clear - can you suggest any ways to improve this transition from face-to-face to online?

After some piloting, the discussion board was arranged to make each question a new thread, to ensure a clear way of displaying the research topics. As the discussions unfolded, the research assistant made additions to research topics where appropriate, usually when the conversations between the participants highlighted anything that had not already been covered directly. The discussion board was updated, usually once or twice a week, with a series of new threads.

\section{Step nine}

The initial information sheet included the possibility of individual email questions being sent to participants in addition to the discussion board. Four weeks into the discussion board process, one of the topics to research dealt with the group work activities that the 


\section{Case Studies}

participants had needed to complete in the module. However, the nature of the discussion board meant that - while it ensured the anonymity of the participants from the rest of the project team - the participants' identities were known to each other. For this stage of the research, therefore, the discussion board was not suitable, as specific comments could be seen by other group members. To avoid this, the research assistant used the email question format for three discussion points concerning group work; for example:

Do you have any comments about the amount and the quality of engagement with the tasks within your group?

\section{Guidance for others}

The first lesson learnt was the value of taking the co-creation approach in contrast to just eliciting feedback. The results of these steps were that the students' comments were expansive (20,000 words on discussion boards and emails) and very frank (exhibiting a wide range of emotions, forcefully exchanged), consequently enabling us to redesign the module without the major mistakes of the pilot. The revised module will now use much less online engagement than initially envisaged and be less complex in the flow of tasks the students are to perform.

Secondly, the project served as a pertinent and salient reminder of the ontology of research carried out in the interpretivist paradigm, and within the paradigm of complexity systems. We had to remind ourselves constantly that the research was not intended to discover any underlying truth about what actually happened during the pilot, but rather to find out the interpretations of different stakeholders - in this case students - and what they felt was happening. One example concerns a claim that the instructions for a certain task were inadequate for a certain task. However, there is no value in countering this with a tutor disclaimer that there were lengthy instructions. What is important is the belief (and the sharing of that belief amongst students) concerning those instructions. Further, the paradigm of complexity systems recognises that such countering views of reality provide the context the researchers are trying to understand.

Thirdly, the project showed us the error of making assumptions about students' likes, dislikes, behaviours and expectations concerning their online lives. Though the specific findings concerning this are beyond the remit of this paper, the partnership approach enabled us to realise how wide of the mark our previous assumptions had been.

Finally, the project confirmed for us the need to embrace the ideas of complexity systems research as outlined above, in particular the need to look at situations through the eyes of different stakeholders. The dilemma discussed earlier, inadvertently arising from the conflicting constraints imposed by, respectively, the HEA and the QAA, also relates to such complexity, embodying, as it does, a clash of expectations and thus creating tensions. We needed to recognise that this dilemma is not something to be resolved, but something which must be accommodated within the workings of our community of practice. As an example, we started this project confident that the teaching materials, and the structuring of these materials, would satisfy the institutional requirements as to what amounts to 'contact time'. We also believed that the materials would be liked by the students. The research revealed, however, that there is a fundamental (and ideologically-based) disagreement concerning this 


\section{Case Studies}

key aspect of blended learning and hence the strategic changes under way in this institution. The institutional view, like that of the QAA (2011), is that contact time can include both faceto-face and online (synchronous and asynchronous) engagements. The students, however, really restrict their definition of contact time to face-to-face or synchronous online contact with tutors. They do not include asynchronous contact with tutors, nor contact with the materials, nor contact with other students. This, given the context for the current changes outlined earlier, is an issue which has ramifications far beyond this particular module and it links directly to issues of learning organisations and complexity theories. This approach has therefore identified a key area - in this context of situation - where there is a need for systemic thinking to achieve greater alignment and coherence throughout the complex organisation of the University if the institutional objectives are to succeed.

\section{Reference list}

Cohen, L., Manion, L. and Morrison, K. (2007) Research Methods in Education (7th ed.). Abingdon: Routledge.

Crystal, D. (2008) A Dictionary of Linguistics and Phonetics (6th ed.). ISBN: 978-1-40515296-9. Available at: http://onlinelibrary.wiley.com/doi/10.1002/9781444302776.fmatter/pdf (Accessed: 20 June 2017).

Higher Education Academy (HEA) (2011) The UK Professional Standards Framework for teaching and supporting learning in higher education. Available at:

https://www.heacademy.ac.uk/system/files/downloads/uk professional standards framewor k.pdf (Accessed: 20 June 2017).

Malinowski, B. (1994 [1923]) 'The Problem of Meaning in Primitive Languages.' In: Maybin, J. (ed.) Language and Literacy in Social Practice. Clevedon: Multilingual Matters Ltd., 1-10.

McPherson, N. G. and Heggie, G. (2015) Transitioning to Students as Partners, Producers, Collaborators and Co-creators. Are We Serious? Available at: https://www.researchgate.net/ (Accessed: 8 February 2017).

Money, J., Dinning, T., Nixon, S., Walsh, B. and Magill, C. (2016) 'Co-Creating a Blended Learning Curriculum in Transition to Higher Education: A Student Viewpoint.' Creative Education, 7, 1205-1213. Available at: http://file.scirp.org/pdf/CE 2016062016531078.pdf (Accessed: 20 June 2017).

Quality Assurance Agency (QAA) (2011) Explaining contact hours. Available at: http://www.qaa.ac.uk/en/Publications/Documents/contact-hours.pdf (Accessed: 8 February 2017).

Quality Assurance Agency (QAA) (2015) The UK Quality Code for Higher Education.

Available at: $\underline{\text { http://www.qaa.ac.uk/publications/information-and- }}$ guidance/publication?PubID=180\#.WRw5-ty1t8c (Accessed: 20 June 2017).

Smith, M. K. (2001, 2007) The Learning Organization. Available at: http://infed.org/mobi/thelearning-organization/ (Accessed: 20 June 2017). 
Case Studies

Watson, W.R. and Watson, S. L. (2013) 'Exploding the Ivory Tower: Systemic Change for Higher Education.' TechTrends 57 (5). Available at:

https://link.springer.com/article/10.1007/s11528-013-0690-9 (Accessed: 20 June 2017). 